\title{
Repair of a canine patellar ligament rupture using the ComPact UniLock 2.4/3.0 mm System
}

Gutbrod, Andreas ; Kühn, Karolin ; Wiestner, Thomas ; Kircher, Patrick R ; Hurter, K

\begin{abstract}
Eine 11-jährige, kastrierte Mischlingshündin wurde nach einem Autounfall mit einem Riss des linken Patellarbandes vorgestellt. Aufgrund einer vermuteten Wundinfektion im Bereich des Kniegelenks wurde eine chirurgische Versorgung der Patellarbandruptur erst nach 10 Tagen durchgeführt. Das gerissene Band wurde genäht und mit Faszia lata Streifen verstärkt. Um die primäre Naht zusätzlich zu schützen, wurden zwei ComPact UniLock 2.4/3.0 mm Platten verwendet, die über $1.0 \mathrm{~mm}$ orthopädischen Draht verbunden wurden. Eine Ruhigstellung des Kniegelenks war nicht notwendig. Nach 7 Wochen wurden die Implantate wegen einer Infektion und Lockerung entfernt. Die erfolgreiche Anwendung einer alternativen chirurgischen Technik für die Behandlung einer Ruptur des Kniescheibenbandes beim Hund wurde auch durch prä- und postoperative Ganganalysen (GaitFour ${ }^{\circledR}$ ) dokumentiert.
\end{abstract}

DOI: https://doi.org/10.1024/0036-7281/a000500

Posted at the Zurich Open Repository and Archive, University of Zurich

ZORA URL: https://doi.org/10.5167/uzh-88048

Journal Article

Accepted Version

Originally published at:

Gutbrod, Andreas; Kühn, Karolin; Wiestner, Thomas; Kircher, Patrick R; Hurter, K (2013). Repair of a canine patellar ligament rupture using the ComPact UniLock 2.4/3.0 mm System. Schweizer Archiv für Tierheilkunde, 155(9):505-509.

DOI: https://doi.org/10.1024/0036-7281/a000500 
1 Repair of a canine patellar ligament rupture using the ComPact UniLock $2.4 / 3.0 \mathrm{~mm}$

2 System

3 A. Gutbrod ${ }^{1}$, K. Kühn ${ }^{2}$, T. Wiestner ${ }^{3}$, P. Kircher ${ }^{2}$, K. Hurter ${ }^{1}$

$4 \quad{ }^{1}$ Department of Small Animal Surgery, ${ }^{2}$ Section of Diagnostic Imaging and ${ }^{3}$ Equine

5 Department, University of Zurich, Zurich, Switzerland

6

7 Summary

8 An 11-year old, female, Mix Breed dog was presented after being hit by a car with a rupture

9 of the left patellar ligament. Due to a suspected wound infection close to the stifle joint,

10 surgical repair was delayed for 10 days. The ruptured ligament was sutured and augmented

11 with fascia lata. Additionally, two ComPact UniLock 2.4/3.0 mm plates connected with 1.0

$12 \mathrm{~mm}$ orthopaedic wire were used to protect the primary repair. No immobilization of the

13 stifle joint was needed. The implants were removed after 7 weeks, because of suspected

14 infection and loosening. The successful utilization of an alternative surgical technique for the

15 repair of the patellar ligament rupture in the dog has also been documented by pre- and

16 post-operative temporal-spatial gait analysis (GaitFour $\left.{ }^{\circledR}\right)$.

17 Keywords: dog, patellar ligament, rupture, UniLock, trauma

19 Chirurgische Behandlung einer Ruptur des Kniescheibenbandes beim Hund mit ComPact

20 UniLock 2.4/3.0 mm System

21 Zusammenfassung

22 Eine 11-jährige, kastrierte Mischlingshündin wurde nach einem Autounfall mit einem Riss

23 des linken Patellarbandes vorgestellt. Aufgrund einer vermuteten Wundinfektion im Bereich

24 des Kniegelenks wurde eine chirurgische Versorgung der Patellarbandruptur erst nach 10

25 Tagen durchgeführt. Das gerissene Band wurde genäht und mit Faszia lata Streifen verstärkt.

26 Um die primäre Naht zusätzlich zu schützen, wurden zwei ComPact UniLock 2.4/3.0 mm

27 Platten verwendet, die über $1.0 \mathrm{~mm}$ orthopädischen Draht verbunden wurden. Eine

28 Ruhigstellung des Kniegelenks war nicht notwendig. Nach 7 Wochen wurden die Implantate

29 wegen einer Infektion und Lockerung entfernt. Die erfolgreiche Anwendung einer

30 alternativen chirurgischen Technik für die Behandlung einer Ruptur des Kniescheibenbandes

31 beim Hund wurde auch durch prä- und postoperative Ganganalysen (GaitFour ${ }^{\oplus}$ )

32 dokumentiert.

33 Schlüsselwörter: Hund, Patellarligament, Ruptur, UniLock, Trauma 
Rupture of the canine patellar ligament is a rare injury and primary surgical repair of the ruptured ligament in combination with an internal splint to protect the suture is recommended (Piermattei et al., 2006; Shipov et al., 2008; Archer et al., 2010). This has been achieved using orthopaedic wire, fishing line or augmentation with fascia lata with a favourable prognosis. This case report describes an alternative approach for internal splinting of the patellar ligament using two ComPact UniLock $2.4 / 3.0 \mathrm{~mm}$ plates, one fixed to the patella and one to the tibial tuberosity, connected with $1.0 \mathrm{~mm}$ orthopaedic wire.

\section{Clinical examination}

An 11-year old, female, spayed Mix Breed dog was presented to the Small Animal Clinic of the University of Zürich after being hit by a car. After hemodynamical stabilization and treatment of the open skin wounds including antibiotic therapy with cefalexin (Kefzol ${ }^{\circledR}$, Teva Pharma AG, 4147 Aesch, Switzerland) and enrofloxacin (Baytril ${ }^{\circledR}$, Provet AG, 3421 Lyssach, Switzerland), a complete orthopaedic and neurologic exam was performed. An obvious lameness without weight bearing during trotting was observed in the left hind limb with an inability to maintain stifle extension during the stance phase. Severe swelling of the left stifle, a proximally displaced patella and a depression cranial at the level of the patellar ligament were noted. No neurologic deficits or further lameness was detected. Radiographs of both stifle joints (Fig. 1) and an ultrasonographic examination of the left patellar ligament were performed to confirm the clinical diagnosis of patellar ligament rupture. To minimize the risk of infection surgical repair of the patellar ligament was delayed for 10 days.

One day prior to surgery a temporal-spatial gait analysis was performed using a pressure sensitive walkway (GaitFour ${ }^{\circledR}$, Sparta, NJ, USA) in order to obtain the total pressure index and the number of activated sensors per footstep. The values for the affected and unaffected limbs were compared and an asymmetry index was calculated. This showed a marked favouring of the unaffected limb during weight bearing with higher values for the total pressure index and activated sensors (Tab. 1).

\section{Arthroscopy}

Ten days after the trauma the dog an arthroscopic exploration of the stifle joint was performed using a $1.9 \mathrm{~mm}$ arthroscope and standard portal sites (Schulz, 2012). A complete rupture of the patellar ligament was observed at the level of the insertion at the tibial 
tuberosity. The patellar ligament was swollen, soft, frayed and markedly inflamed. The cruciate ligaments, menisci and the cartilage were unremarkable.

\section{Surgical technique}

The proximal tibial tuberosity, the cranial aspect of the patella and the patellar ligament with its torn fibers were then exposed A primary repair of the ligament was performed with two Ethibond ${ }^{\circledR}$ sutures (USP 6 and USP 1) applying a locking-loop in the proximal part and a fixation through a transverse drill hole in the tibia at the level of the insertion. This repair was additionally supported in the following way: The proximal aspect of a 6 hole $2.4 / 3.0 \mathrm{~mm}$ ComPact UniLock (Synthes Gmbh \& Co KG, Umkirch, Germany) plate was contoured to fit the shape of the cranial margin of the patella and attached to the patella using two $2.4 \mathrm{~mm}$ locking screws ensuring that the tip was not protruding over the articular surface. A second plate was placed on the cranial aspect of the tibial tuberosity using 3 monocortical locking screws leaving the most proximal screw hole empty and protruding proximal over the tibial tuberosity. The most distal plate hole of the proximal plate was connected to the proximal plate hole of the distal plate with two $1.0 \mathrm{~mm}$ orthopaedic wires. The two wires were alternately tightened until the distance of the apex patella and tibial tuberosity matched the preoperatively measured distance in the contralateral stifle (Fig. 2). To augment the extensor mechanism of the stifle additional fascia lata strips were used. Patellar ligament plating was performed suturing the patellar ligament to the proximal plate using 0 PDS in a simple interrupted pattern. The surgery site was flushed with copious amounts of sterile saline and a gentamycin soaked collagen sponge (Garamycin ${ }^{\circledR} 50 \mathrm{mg}$ ) was placed near the implants. No external stabilization of the stifle joint was applied. Antibiotic treatment was continued.

\section{Postoperative care and outcome}

93 The orthopaedic exam on the first day after surgery showed only an intermittent and consistently weight bearing lameness of the left hind limb with normal joint angles during walk. The temporal-spatial gait analysis showed a reduction for the asymmetry indices for the TPI and the activated sensors compared to preoperative values. This indicated an improved weight bearing in the operated leg (Tab. 1). Three days after surgery the lameness gradually worsened and a the cytology after fine needle aspiration of the periarticular tissue showed a purulent inflammation with 
100 degenerated neutrophils and coagulase negative staphylococci were isolated resistant to the

101 antibiotics the dog received. The antibiotic treatment was switched to clindamycin

102 (Antirobe $^{\circledR}$, Pfizer AG, Zürich, Switzerland) and the leg was placed in a modified Robert-Jones

103 bandage for 2 days. The swelling decreased within 2 days and the gait improved markedly to

104 an intermittent and consistently weight bearing lameness again. For the next 7 weeks on

105 weekly clinical exams and according to the owner no lameness was observed. The temporal-

106 spatial gait analysis at this time also showed a reduction for the asymmetry indices for the

107 TPI and the activated sensors compared to preoperative values.

108 All implants were removed after 7 weeks, since radiographic examinations (Fig. 3) showed

109 signs of implant loosening.

110 No hind limb lameness was observed 14 days after implant removal. After temporal-spatial

111 gait analysis the asymmetry indices for the TPI and the number of activated sensors were

112 calculated and the results comparable to the immediate post operative values (Tab. 1).

113 Three weeks after implant removal the dog presented with neck pain and radiographs of

114 thoracic spine showed an aggressive polyostotic bone lesion involving Th2 to Th4. However

115 the owner declined further diagnostics and treatment and the patient was empirically

116 treated for suspected discospondylitis.The owner decided to euthanize the $\operatorname{dog} 5 \frac{1}{2}$ month

117 after the patellar ligament repair at their local veterinarian due to worsening of the neck

118 pain.

\section{Discussion}

121 In this report we describe a successful treatment of a traumatic patellar ligament rupture

122 using two ComPact UniLock $2.4 / 3.0 \mathrm{~mm}$ plates fixated in the patella and the tibial tuberosity

123 respectively, connected with $1.0 \mathrm{~mm}$ orthopaedic wire. After healing an excellent outcome

124 was observed clinically without lameness, an unrestricted range of motion and normal joint

125 angles during ambulation. This was further supported by the results of the temporal-spatial

126 gait analysis.

127 The decision to use this alternative approach was based on the substantial defect in the 128 patellar ligament as well as the marked inflammation of the soft tissues, which weakened

129 the fascia lata and the patellar ligament further. A very stable internal fixation would be 130 required to protect the primary repair and persistent lameness has been described in cases

131 of large defects treated with traditional techniques (Gemmill and Carmichael, 2003). In a

132 different case a single plate spanning the patellar ligament from the tibial tuberosity to the 
133 patella has been used before. However this plate broke and in a second operation the

134 surgeon linked the two broken plate segments awith orthopaedic wire. As this revision

135 showed success we directly used two ComPact UniLock $2.4 / 3.0 \mathrm{~mm}$ plates fixed individually

136 to the patella and tibial tuberosity, connected via two $1.0 \mathrm{~mm}$ orthopaedic wires maintaining

137 the distance of the patella to the tibia and allowing full range of motion in the stifle joint in

138 this case.

139 The most commonly described repair of patellar ligament ruptures is the placement of

140 locking loop sutures with large nonabsorbable suture material and an internal splint. (Shipov

141 et al., 2008; Archer et al., 2010). Additional stability can be achieved by augmenting the

142 repair with autogenous fascia lata grafts (Aron et al., 1997; Gemmill and Carmichael, 2003).

143 The use of transarticular splints, transarticular external fixateurs, or patellar ligament plating

144 has also been described for further protection of the primary repair with little additional

145 morbidity (Kowaleski et al., 2012). The benefit of our construct was that beyond relieving

146 tension on the primary repair of the patellar ligament, the proximal plate was used for

147 ligament plating simultaneously.

148 Immobilization of the stifle joint postoperatively has been suggested with the aid of

149 transarticular external fixateurs or transarticular casts or splints (Smith et al., 2000; Shipov et

150 al., 2008). The amount of necessary immobilization however is controversial. It is known that

151 in dogs transarticular external fixateurs reduce the blood supply to injured tendons

152 significantly (Gelberman et al., 1980). Reduced range of motion in the stifle joint can also

153 result. Therefore in human medicine currently a limited immediate mobilization is

154 recommended to decrease adhesion formation, cartilage damage and prevent a limited

155 range of motion (Kasten et al., 2001; Grim et al., 2010). This will also result in a stronger

156 repair, that resembles the histological features of a normal tendon better than a tendon

157 healing while immobilized (Gelberman et al., 1980). We decided to avoid further external

158 immobilization, since this technique provides sufficient internal stability.

159 In order to limit the risk of a postoperative infection, repair of the ruptured ligament was

160 delayed and wound management was initiated to generate healthy granulation tissue in the

161 injured stifle area prior to surgery. Further measures to prevent surgical site infection were

162 strict aseptic preparations, placement of gentamycin sponges during surgery and the use of

163 titanium implants, which are less susceptible to infection (Arens et al., 1996). An arthrotomy

164 was also avoided. However infection and associated implant loosening could not be averted.

165 Whether the implant loosening was due to the infection or due to weak implant seating and 
cyclic loading cannot be distinguished. Reasons for the infection might have been the multiple wounds, the polytrauma the patient had suffered and the presence of implants.

168 The use of braided multifilament suture material like Ethibond might have also predisposed

169 to bacterial infection and should be avoided in similar cases in the future.

170 Prognosis after surgical repair of patellar tendon rupture has been described as fair to good,

171 although in the experience of the authors a less favourable outcome seems more common.

172 In addition to the more or less subjective orthopaedic exams, an impartial outcome

173 measurement was intended using temporal-spatial gait analysis on a pressure sensitive

174 walkway (GaitFour ${ }^{\circledR}$ ). This method has been validated in healthy dogs (Viguier et al., 2007;

175 Light et al., 2010) and used clinically in dogs with spinal cord disease (Gordon-Evans et al.,

176 2009). Gait analysis in the presented dog showed an immediate postoperative return to the

177 weight bearing of the contralateral hind leg, which was maintained over three months.

178 However during the healing process complications could not be avoided and lameness

179 recurred and had to be controlled with antibiotics and analgetics until the implants were

180 removed.

181 This case shows the successful treatment of a traumatic rupture of the patellar ligament

182 with a substantial loss in the integrity of the ligament and a local infection using two 2.4/3.0

$183 \mathrm{~mm}$ ComPact UniLock plates linked flexible with two orthopaedic wires. No external

184 coaptation or transarticular fixateur was needed. Further evaluations of this technique are 185 needed to show its benefits in relation to comparable methods.

\section{References}

189 Archer R. M., Sissener T. R., Spotswood T.C.: What is your diagnosis? Patellar tendon rupture. 190 J. Am. Vet. Med. Assoc. 2010, 237: 273-274.

192 Arens S., Schlegel U., Printzen G.: Influence of materials for fixation implants on local 193 infection. An experimental study of steel versus titanium DCP in rabbits. J. Bone Joint Surg. 194 Br. 1996, 78: 647-651. 
200 Aron D., Selcer B., Smith J.: Autogenous Tensor Fascia Lata Graft Replacement of the Patellar 201 Ligament in a Dog. Vet. Comp. Orthop. Traumatol. 1997, 10: 141-145.

202

203 Culvenor J.A.: Fascia lata flap to reinforce repair of patella ligament injuries in the dog and 204 cat. J. Am. Vet. Med. Assoc. 1988, 29: 559-563.

205

206 Fahie M.A.: Healing, diagnosis, repair, and rehabilitation of tendon conditions. Vet. Clin.

207 North. Am. Small. Anim. Pract. 2005, 35: 1195-1211

208

Gelberman R.H., Menon J., Gonsalves M.: The effects of mobilization on the vascularization of healing flexor tendons in dogs. Clin. Orthop. Relat. Res. 1980 153: 283-289.

Gemmill T.J., Carmichael S.: Complete patellar ligament replacement using a fascia lata autograft in a dog. J. Small. Anim. Pract. 2003 44: 456-459.

Gordon-Evans W.J., Evans R.B., Knap K.E., Hildreth J. M., Pinel C. B., Imhoff D. J., Conzemius M. G.,: Characterization of spatiotemporal gait characteristics in clinically normal dogs and dogs with spinal cord disease. Am. J. Vet. Res. 2009, 70: 1444-1449.

Greis P. E., Holmstrom M. C. , Lahav A.: Surgical treatment options for patella tendon rupture, Part I: Acute. Orthopedics 2005, 7: 672-679.

Grim C., Lorbach O., Engelhardt M.: [Quadriceps and patellar tendon ruptures]. Der

Orthopäde. 2010, 12: 1127-1134.

Kasten P., Schewe B., Maurer F.: Rupture of the patellar tendon: a review of 68 cases and a retrospective study of 29 ruptures comparing two methods of augmentation. Arch. Orthop. Trauma. Surg. 2001, 121: 578-582. 
232 Light V., Steiss J., Montgomery R.: Temporal-spatial gait analysis by use of a portable

233 walkway system in healthy Labrador Retrievers at a walk. Am. J. Vet. Res. 2010, 71: 997-1002.

235 Piermattei D., Flo G., DeCamp C.: The Stifle Joint, In: Brinker, Piermattei, and Flo's Handbook

236 of Small Animal Orthopedics and Fracture Repair. 4. Auflage, Saunders Elsevier, St. Louis

237 Missouri, 2006, 622-623.

238

239 Schulz K.S.: Arthroscopy of the Stifle Joint. In: Veterinary Surgery Small Animal., Hrsg: K.M.

240 Tobias, S. A. Johnston, Elsevier, St. Louis, Missouri, 2012, 1154 - 1158.

241

242 Shipov A., Shahar R., Joseph R., Milgram J.: Successful management of bilateral patellar

243 tendon rupture in a dog. Vet. Comp. Orthop. Traumatol. 2008, 21: 181-184.

244

245 Smith M., de Haan J., Peck J, Madden S.N.: Augmented primary repair of patellar ligament

246 rupture in three dogs. Vet. Comp. Orthop. Traumatol. 2000, 13: 154-157.

248 Viguier E., Le Quang T., Maitre P., Gaudin A., Rawling M., Hass D.: The validity and reliability 249 of the GAITRite ${ }^{\circledR}$ system's measurement of the walking dog. Comput. Methods. Biomech.

250 Biomed. Engin. 2007, 10: 113-114.

251

252 Corresponding author

253 Andreas Gutbrod

254 Department of Small Animal Surgery

255 Vetsuisse Faculty, University of Zurich

256 Winterthurerstrasse 260

$257 \mathrm{CH}-8057$ Zurich

258 Switzerland

259 agutbrod@vetclinics.uzh.ch 